\title{
Long-term oral nitrate therapy is associated with adverse outcome in diabetic patients following elective percutaneous coronary intervention
}

\author{
Kai Hang Yiu, Vincent Pong, Chung Wah Siu, Chu Pak Lau and Hung Fat Tse
}

\begin{abstract}
Background: To assess the impact of long-term oral nitrate therapy on clinical outcome following percutaneous coronary intervention (PCI) in patients with type II diabetes.

Methods: The incidence of major adverse cardiovascular events (MACEs) following elective PCI for stable coronary artery disease was evaluated in 108 patients with type II diabetes (age $64.6 \pm 10.5$ years, 67.7\% men). Major adverse cardiovascular events were defined as the need for revascularization, non-fatal myocardial infarction or cardiovascular death. Multivariate Cox regression analysis was used to evaluate the predictive value of MACEs by clinical characteristics and the prescription of long-term nitrate therapy.

Results: Isosorbide mononitrate (ISMN) was prescribed to 46 patients with an average dose of $44.3 \pm 15.2 \mathrm{mg} /$ day. After a mean follow up of $25.3 \pm 25$ months, 16 patients developed MACEs. Patients who received ISMN were more likely to suffer from MACEs ( $26.1 \%$ vs. $6.5 \%, P=0.01)$, mainly driven by a higher rate of acute coronary syndrome (13.0 vs 0\%, $P=0.01$ ). Average daily dose of nitrate and other cardiovascular medication was not associated with MACEs. Multivariate Cox regression analysis revealed that prescription of only ISMN (Hazard Ratio $3.09,95 \% \mathrm{Cl} 1.10-10.21, \mathrm{P}=0.04$ ) was an independent predictor for the development of MACEs.
\end{abstract}

Conclusion: Long-term oral nitrate therapy was associated with MACEs following elective coronary artery revascularization by $\mathrm{PCl}$ in patients with type II diabetes.

Keywords: Nitrate, Diabetes, MACEs

\section{Introduction}

Elective percutaneous coronary intervention (PCI) is a common treatment for patients with stable coronary artery disease and comprises $85 \%$ of all $\mathrm{PCI}$ procedures $[1,2]$. Diabetic patients account for up to one quarter of patients who undergo PCI each year and experience a higher rate of post-operative adverse cardiovascular events than non-diabetics [3].

Organic nitrate remains one of the most frequently prescribed anti-anginal agents for the treatment of coronary artery disease (CAD), although no long-term beneficial effect has been proven [4]. Previous clinical trials have suggested that continuous administration of oral nitrates paradoxically increases adverse cardiac events

\footnotetext{
* Correspondence: hftse@hku.hk

Division of Cardiology, Department of Medicine, Queen Mary Hospital, The University of Hong Kong, Hong Kong
}

following myocardial infarction [5-7]. It is nonetheless remains unknown whether the use of oral nitrates following elective PCI has a deleterious effect in patients with diabetes. The objective of this study was to determine the impact of long-term oral nitrate therapy on clinical outcome in patients with type II diabetes who undergo elective PCI for stable CAD.

\section{Methods}

Conts ical symptoms who underwent successful elective PCI and coronary stenting for stable CAD between March 2003 and September 2005 were recruited. All patients had type II diabetes as defined by the American Diabetic Association [8], and were prescribed a hypoglycemic agent (oral antidiabetic agents or insulin). Patients 
were excluded if they had terminal malignancy, congestive heart failure, incomplete or failed revascularization (residual stenosis $>50 \%$ in any one of the three major coronary arteries), significant left main CAD > 50\% stenosis, recent stroke or acute coronary syndrome in the past 3 months. There was no restriction in terms of usage of either bare metal or drug eluting stents.

\section{Study Design}

Baseline clinical characteristics including body weight, height, and routine blood biochemistry were documented in all patients during their admission for PCI. Left ventricular ejection fraction (LVEF) was also evaluated by transthoracic echocardiography before PCI and patients were categorized as having preserved LVEF $\geq 50 \%$ or impaired LVEF $<50 \%$. Data on medication prescribed before and after PCI were ascertained from the hospital computer system. Patients prescribed oral nitrate were given long release isosorbide-5-mononitrate (ISMN). All patients were followed up regularly in our clinic every 3-4 months. Data concerning all hospital admissions and death were retrieved from the hospital electronic record system. During the study period, no patients were lost to follow up. The presence of triple CAD was defined as the presence of lesions in all three major coronary arteries that were either successfully revascularized or had $<50 \%$ residual stenosis. This study was approved by the local institutional ethic committee.

The endpoint of this study was the occurrence of major adverse cardiovascular events (MACEs) including (1) the need for targeted vessel revascularization due to in-stent restenosis, or (2) non-fatal myocardial infarction, defined as the presence of symptoms consistent with the World Health Organization criteria [9], associated with abnormal levels of necrosis markers (including troponin) or diagnostic electrocardiogram changes, and (3) cardiovascular mortality (sudden cardiac death, fatal stroke, myocardial infarction and heart failure).

\section{Statistical Analysis}

Continuous variables are presented as mean \pm 1 standard deviation. Categorical data are presented as frequencies and percentages. Statistical comparisons were performed with Mann-Whitney $U$ test or Chi-squared test, as appropriate. The association between clinical characteristics, underlying triple vessel disease and cardiac medication and the risk of MACEs was analyzed using Cox proportional hazards models. Multivariate analysis was performed with an enter regression model, in which each variable with a $\mathrm{P}$ value $\leq 0.1$ (based on the univariate analysis) was entered into the model. Calculations were performed using SPSS software (version
15.0). A P value $<0.05$ was considered statistically significant.

\section{Results \\ Baseline demographics}

A total of 280 patients underwent elective PCI and 108 patients who satisfied the inclusion criteria were followed up for a mean period of $25.3 \pm 25$ months. Their mean age was $64.6 \pm 10.5$ years and $67.6 \%$ were men. In total, 20 patients $(18.5 \%)$ required insulin therapy and the mean HbA1c level was $7.8 \pm 2.2 \%$. The body mass index was $25.7 \pm 3.8 \mathrm{~kg} / \mathrm{m}^{2}$. Triple vessel disease was present in 14 patients (11.1\%) and 34 (31.5\%) had undergone previous percutaneous intervention. A total of 20 patients $(18.5 \%)$ had impaired LVEF $<50 \%$. Betablocker, statin and angiotensin converting enzyme inhibitor or angiotensin receptor blocker was prescribed to $>80 \%$ of patients.

A total of 46 patients received ISMN therapy, prescribed for at least 1 month prior to PCI. The mean duration of ISMN therapy before PCI was $258.2 \pm 169.7$ days and the total duration of ISMN therapy before and after PCI was $816.1 \pm 691.7$ days. The mean total ISMN dose received per patient was $38.6 \pm 40.7 \mathrm{gm}$ and the average daily dose was $44.3 \pm 15.2 \mathrm{mg} /$ day. The baseline demographics of patients with and without ISMN therapy are shown in Table 1 . There were no significant differences in terms of age, conventional cardiovascular risk factors or use of concomitant medication $(\mathrm{P}>0.05)$. Patients who received ISMN were nonetheless more likely to suffer from underlying triple vessel disease (23.9 vs. $4.8 \%, \mathrm{P}=0.01$ ).

\section{Major adverse cardiovascular events}

The clinical outcomes of the study population are summarized in Table 2. Overall, 16 patients (14.8\%) developed MACEs and all-cause mortality was 4.6\%. Among patients with MACEs, 7 developed in-stent restenosis that required repeat revascularization (presented with crescendo angina) and 6 were hospitalized for non-fatal myocardial infarction. Cardiovascular death occurred in 3 (sudden death in 1 patient and fatal stroke in 2). Patients who received ISMN were more likely to suffer from MACEs ( 26.1 vs. $6.5 \%, \mathrm{P}<0.01$ ), mainly driven by a higher rate of non-fatal myocardial infarction (13 vs. $0 \% \mathrm{P}<0.01$ ) (Table 2 ). There were no differences in occurrence of in-stent restenosis, cardiovascular mortality or all-cause mortality between patients with and without ISMN therapy.

The MACEs and all-cause mortality-free survival curves of patients with and without ISMN therapy are shown in Figure 1 and 2, respectively. During a follow up of over 40 months, the cumulative incidence of 
Table 1 Baseline characteristics between patients with and without ISMN

\begin{tabular}{|c|c|c|c|}
\hline Variable & Without ISMN $(n=62)$ & With ISMN $(n=46)$ & $P$ value \\
\hline \multicolumn{4}{|l|}{ Baseline Demographics } \\
\hline Age, years & $64.3 \pm 10.1$ & $65.0 \pm 11.1$ & 0.75 \\
\hline Male, n (\%) & $42(67.7)$ & $31(86.1)$ & 1.0 \\
\hline Body mass index, $\mathrm{kg} / \mathrm{m}^{2}$ & $26.3 \pm 3.9$ & $25.0 \pm 3.6$ & 0.09 \\
\hline Hypertension, n (\%) & $15(24.2)$ & $5(10.9)$ & 0.09 \\
\hline Smoking, n (\%) & $29(46.8)$ & $23(50.0)$ & 0.70 \\
\hline Insulin therapy, n (\%) & 13(21.0) & $7(15.2)$ & 0.62 \\
\hline Creatinine, $\mathrm{mmol} / \mathrm{L}$ & $141.1 \pm 137.4$ & $128.8 \pm 91.9$ & 0.59 \\
\hline $\mathrm{HbA} 1 \mathrm{c}, \%$ & $7.8 \pm 2.6$ & $7.8 \pm 1.4$ & 0.92 \\
\hline Total cholesterol, mmol/L & $4.4 \pm 1.0$ & $4.5 \pm 1.3$ & 0.88 \\
\hline Triglyceride, $\mathrm{mmol} / \mathrm{L}$ & $1.9 \pm 1.6$ & $2.1 \pm 4.0$ & 0.76 \\
\hline $\mathrm{HDL}$ cholesterol, $\mathrm{mmol} / \mathrm{L}$ & $1.1 \pm 0.2$ & $1.2 \pm 0.2$ & 0.18 \\
\hline LDL cholesterol, mmol/L & $2.6 \pm 0.9$ & $2.5 \pm .7$ & 0.76 \\
\hline Triple vessel disease, n (\%) & $3(4.8)$ & $11(23.9)$ & ${ }^{*} 0.01$ \\
\hline Prior myocardial infarction, n (\%) & $15(24.2)$ & 18(39.1) & 0.14 \\
\hline Prior $\mathrm{PCl}, \mathrm{n}(\%)$ & $17(27.4)$ & 18(39.1) & 0.21 \\
\hline Drug eluting stent, $\mathrm{n}(\%)$ & $43(69.4)$ & $31(67.4)$ & 0.84 \\
\hline Impaired LVEF < 50\%, n(\%) & 13(21.0) & $7(15.2)$ & 0.62 \\
\hline \multicolumn{4}{|l|}{ Medications after $\mathrm{PCl}$} \\
\hline Beta blocker, n (\%) & $50(80.6)$ & $38(82.6)$ & 1.0 \\
\hline Calcium channel blocker, n (\%) & $43(69.4)$ & $29(63.0)$ & 0.40 \\
\hline Statin, n (\%) & $54(87.1)$ & $41(89.1)$ & 1.0 \\
\hline ACEI/ARB, n (\%) & $53(85.5)$ & $39(84.8)$ & 0.77 \\
\hline Aldosterone blocker, n (\%) & $6(9.7)$ & $1(2.2)$ & 0.14 \\
\hline
\end{tabular}

Abbreviation: $\mathrm{ACEI}=$ Angiotensin converting enzyme inhibitor; ARB: Angiotensin receptor blocker; $\mathrm{BMI}=$ Body mass inex, $\mathrm{HDL}=$ High density lipoprotein; ISMN = Isosorbide-5-monitrate; $L D L=$ Low density lipoprotein; $L \mathrm{VEF}=$ Left ventricular ejection fraction; $\mathrm{PCI}=$ Percutaneous coronary intervention;

*: $\mathrm{P}<0.05$.

MACEs was significantly higher in patients with ISMN compared with those without (log-rank test $\mathrm{P}<0.01$ ), although all-cause mortality did not differ. The predictive value of clinical characteristics and medication on MACEs was analyzed by Cox proportional hazards analysis (Table 3). Univariate analysis revealed that age and ISMN were predictors of MACEs. Multivariate analysis demonstrated that only the use of ISMN independently predicted MACEs, not age, creatinine level or triple vessel disease.

\section{Discusssion}

The present results demonstrate that ISMN therapy following elective PCI for stable CAD in patients with type II diabetes is associated with an increased risk of MACEs, mainly driven by an increased risk of non-fatal myocardial infarction. The average dose and total amount of ISMN exposure were nonetheless not associated with the likelihood of developing MACEs.

Previous large trials including the ISIS-4 [10] and GISSI-3 [11] trials have failed to demonstrate any

Table 2 Duration of follow up and incidence of MACE in patients with and without ISMN

\begin{tabular}{|c|c|c|c|c|}
\hline & All $(n=108)$ & Without ISMN (n = 62) & With ISMN $(n=46)$ & $P$ value \\
\hline Duration of Follow-up (months) & $25.3 \pm 25$ & $26.2 \pm 10.8$ & $24.1 \pm 13.5$ & 0.39 \\
\hline MACE, n (\%) & $16(14.8)$ & $4(6.5)$ & $12(26.1)$ & ${ }^{*}<0.01$ \\
\hline Cardiovascular mortality, n (\%) & $3(2.8)$ & $2(3.2)$ & $1(2.2)$ & 1.00 \\
\hline Non-fatal myocardial infarction, n (\%) & $6(5.5)$ & $0(0)$ & $6(13.0)$ & ${ }^{*}<0.01$ \\
\hline In-stent restenosis, n (\%) & $7(6.5)$ & $2(3.2)$ & $5(10.9)$ & 0.13 \\
\hline All cause mortality, n (\%) & $5(4.6)$ & $3(4.8)$ & $2(4.3)$ & 1.00 \\
\hline
\end{tabular}

Abbreviation: Similar to Table 1, MACE: Major adverse cardiovascular events. 


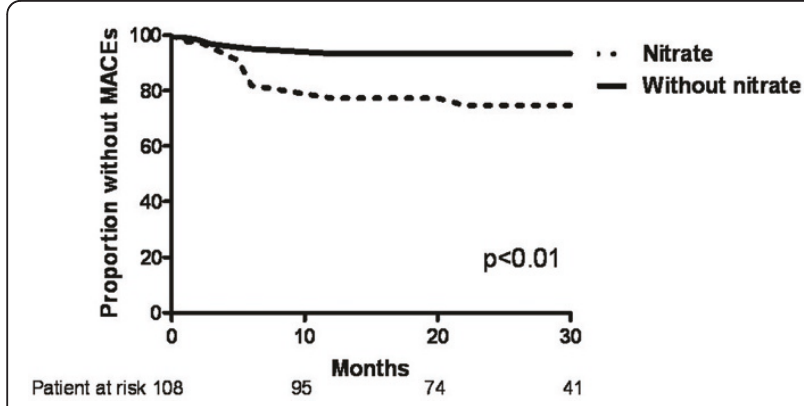

Figure 1 Kaplan-Meier curve for free from major adverse cardiovascular events (MACEs) in patients with and without long-term oral nitrate therapy

beneficial effect of nitrate therapy in post myocardial infarction patients. A recent study of 1000 diabetic patients with acute myocardial infarction revealed that early revascularization and treatment with angiotensin converting enzyme inhibitors, angiotensin II receptor blocker, and aspirin, not nitrates, are associated with improved survival [12]. Previous retrospective studies have also demonstrated that chronic oral nitrate therapy may have a detrimental effect on the long-term outcome for patients with CAD [6,7]. In a study by Nakamura and colleagues, the use of oral nitrate therapy was associated with all-cause mortality in 2821 post myocardial infarction patients [7]. In another study of 1002 myocardial infarction patients randomly assigned to receive or not receive oral nitrate therapy, oral nitrate therapy was associated with adverse cardiac events (fatal or non-fatal recurrent myocardial infarction, congestive heart failure and sudden death). This adverse association has also been found in a prospective open label randomized trial in patients with healed myocardial infarction: patients who received oral nitrate therapy had a significantly higher rate of adverse cardiac events (6.6 vs. $3.1 \%, \mathrm{p}<$ 0.05 ) after 102 months of follow up than those who did not [5]. Our results demonstrate that oral nitrate therapy in diabetic patients who undergo elective PCI is associated with adverse cardiovascular events, mainly

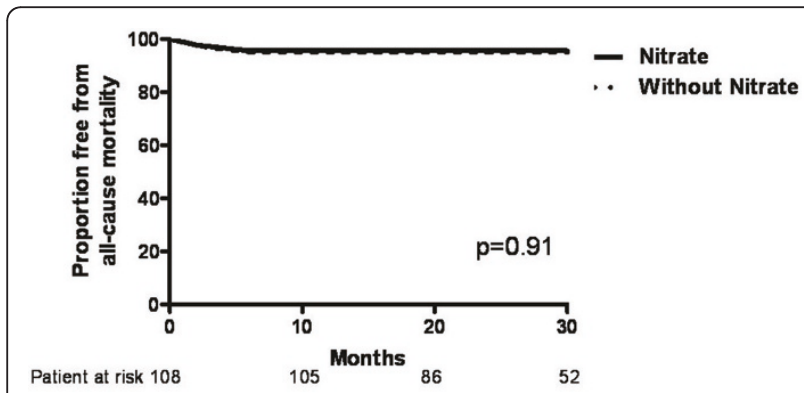

Figure 2 Kaplan-Meier curve for free from all-cause mortality in patients with and without long-term oral nitrate therapy. driven by a higher incidence of non-fatal myocardial infarction. This raises concern about the potential adverse effects of oral nitrate therapy in patients with underlying ischemic heart disease, in particular those with type II diabetes. The recent advent of spinal cord stimulation and enhanced external counterpulsation may offer additional treatment options for patients with refractory angina [13].

Although the use of oral nitrate therapy may be associated with an adverse cardiovascular outcome, the underlying mechanism, particularly in diabetic patients, remains unclear. One of the major limitations of longterm oral nitrate treatment is the rapid diminution of its hemodynamic and anti-ischemic effects as a result of nitrate tolerance. Recent studies have also demonstrated that sustained nitrate therapy is associated with an increased production of reactive oxygen species (ROS) by uncoupling of endothelial nitrate oxide synthase and activation of protein kinase $C$ [14-16]. In addition, hyperglycaemia may cause vascular damage that is mediated through an increased oxidative stress with the generation of ROS, such as superoxide $\left(\mathrm{O}_{2}^{-}\right)$, hydroxyl $(\mathrm{OH})$ and peroxyl $\left(\mathrm{RO}_{2}\right)$ [17-19]. The amplified oxidative stress in patients with type II diabetes and chronic nitrate therapy may aggravate the harmful vascular effects, and contribute to an increased adverse long-term clinical outcome. Another possible explanation of our findings is that the increased platelet aggregating activity in patients with CAD [20] and diabetes [21] following nitrate administration may subsequently lead to higher rates of cardiovascular events. The presence of diabetes and nitrate therapy has recently been shown to be associated with residual platelet reactivity in patients on clopidogrel therapy [22]. This evidence further supports our observation that chronic nitrate therapy may have a detrimental effect in type II diabetic patients with established CAD.

A limitation of our study was its retrospective nature: a randomized, placebo-controlled trial would be preferable. Prescription of medication was at the discretion of individual physicians and the rationale could not be easily qualified from patients' records. Although patients prescribed long term nitrate therapy were likely a group of patients with more angina symptoms (reflecting worse coronary disease), the independent predictive effect of MACEs persisted in such patients despite multivariate adjustment for underlying triple vessel disease. In addition, a significant proportion of diabetic patients may remain asymptomatic due to underlying silent myocardial ischemia. Thus symptom-driven prescription of oral nitrates may not allow accurate identification of diabetic patients with underlying myocardial ischemia. A study involving 310 diabetic patients who underwent coronary angiogram with or without revascularization has demonstrated that asymptomatic diabetic patients 
Table 3 Factors predictive of MACE by Cox regression Model

\begin{tabular}{|c|c|c|c|c|c|c|}
\hline \multirow[b]{2}{*}{ Variable } & \multicolumn{3}{|c|}{ Univariate } & \multicolumn{3}{|c|}{ Multivariate } \\
\hline & HR & $\mathrm{Cl}$ & $P$ value & HR & $\mathrm{Cl}$ & $P$ value \\
\hline \multicolumn{7}{|l|}{ Baseline characteristics } \\
\hline Age, years & 1.03 & $1.01-1.10$ & 0.02 & 1.01 & $0.96-1.06$ & 0.81 \\
\hline Male & 1.31 & $0.42-4.09$ & 0.64 & & & \\
\hline $\mathrm{BMI}$ & 0.92 & $0.81-1.05$ & 0.23 & & & \\
\hline Hypertension & 0.61 & $0.14-2.67$ & 0.51 & & & \\
\hline Smoking & 1.04 & $0.39-2.79$ & 0.93 & & & \\
\hline Insulin therapy & 1.61 & $0.37-7.12$ & 0.53 & & & \\
\hline Creatinine & 1.01 & $1.00-1.02$ & 0.06 & 1.01 & $0.98-1.02$ & 0.12 \\
\hline $\mathrm{HbA1c}$ & 1.04 & $0.72-1.50$ & 0.85 & & & \\
\hline Total cholesterol & 0.84 & $0.45-1.57$ & 0.59 & & & \\
\hline Triglyceride & 0.93 & 0.63-1.39 & 0.73 & & & \\
\hline $\mathrm{HDL}$ & 0.34 & $0.03-4.20$ & 0.40 & & & \\
\hline $\mathrm{LDL}$ & 0.90 & $0.40-1.98$ & 0.79 & & & \\
\hline Triple vessel disease & 3.03 & $0.83-11.07$ & 0.09 & 1.37 & $0.16-11.51$ & 0.77 \\
\hline Prior myocardial infarction & 1.45 & $0.54-4.08$ & 0.45 & & & \\
\hline Prior $\mathrm{PCl}$ & 1.67 & $0.62-4.49$ & 0.31 & & & \\
\hline Drug eluting stent & 0.67 & $0.25-1.82$ & 0.44 & & & \\
\hline Impaired LVEF < 50\% & 1.79 & $0.41-7.87$ & 0.44 & & & \\
\hline \multicolumn{7}{|l|}{ Medications } \\
\hline ISMN & 3.88 & $1.25-12.0$ & 0.02 & 3.09 & $1.19-10.21$ & 0.04 \\
\hline Beta blocker & 2.06 & $0.27-15.67$ & 0.49 & & & \\
\hline $\mathrm{CCB}$ & 1.58 & $0.45-5.59$ & 0.48 & & & \\
\hline Statin & 3.60 & $0.73-17.92$ & 0.12 & & & \\
\hline ACEI/ARB & 1.28 & $0.36-4.53$ & 0.70 & & & \\
\hline Aldosterone blocker, & 0.40 & $0.28-8.21$ & 0.83 & & & \\
\hline
\end{tabular}

Abbreviation similar to Tables 1 and 2 .

have a higher cardiac death risk $(26.4$ vs. $8.8 \%$; $P<$ 0.001 ) compared with well-matched symptomatic diabetic patients during a 5 year follow up [23]. We believe that diabetic patients using oral nitrate may not necessarily represent an excessive higher risk subgroup. Lastly, the small study population may not allow the identification of other potential variables (for example triple vessel disease) that could be associated with MACEs.

\section{Conclusion}

The present study demonstrated that long-term oral nitrate therapy is associated with MACEs following elective PCI for stable coronary artery disease in type II diabetic patients. Although a causal relationship could not be established due to the retrospective design, we believe that our results provide the rationale for a future randomized trial to validate this observation.

\section{Authors' contributions}

$\mathrm{KH}$ participated in the study's design, data collection, statistical analysis and final preparation of the manuscript. VP participated in the data collection of the study. CW and CP participated in the design of the study. HF participated in the study's design and final preparation of the manuscript. All authors read and approved the final manuscript.

\section{Competing interests}

The authors declare that they have no competing interests.

Received: 22 March 2011 Accepted: 13 June 2011 Published: 13 June 2011

\section{References}

1. Fraker TD, Fihn SD, Writing on behalf of the Chronic Stable Angina Writing Committee: Chronic angina focused update of the ACC/AHA 2002 guidelines for the management of patients with chronic stable angina: A report of the American College of Cardiology/American Heart Association task force on practice guidelines writing group to develop the focused update of the 2002 guidelines for the management of patients with chronic stable angina. Circulation 2007, 116:2762-2772.

2. Feldman DN, Gade CL, Slotwiner AJ, Parikh M, Bergman G, Wong SC, Minutello RM, New York State Angioplasty Registry: Comparison of outcomes of percutaneous coronary interventions in patients of three age groups $(<60,60$ to 80 , and $>80$ Years) (from the New York State Angioplasty Registry). Am J Cardiol 2006, 98:1334-1339. 
3. Berry C, Tardif J-C, Bourassa MG: Coronary heart disease in patients with diabetes: Part II: Recent advances in coronary revascularization. J Am Coll Cardiol 2007, 49:643-656.

4. Csont T, Ferdinandy P: Cardioprotective effects of glyceryl trinitrate: beyond vascular nitrate tolerance. Pharmacol Ther 2005, 105:57-68.

5. Ishikawa K, Kanamasa K, Ogawa I, Takenaka T, Naito T, Kamata N, Yamamoto T, Nakai S, Hama J, Oyaizu M, Kimura A, Yamamoto K, Aso N, Arai M, Yabushita H, Katori Y: Long-term nitrate treatment increases cardiac events in patients with healed myocardial infarction. Secondary Prevention Group. Jpn Circ J 1996, 60:788.

6. Kanamasa K, Hayashi T, Kimura A, Ikeda A, Ishikawa K: Long-term, continuous treatment with both oral and transdermal nitrates increases cardiac events in healed myocardial infarction patients. Angiology 2002, 53:399-408.

7. Nakamura Y, Moss AJ, Brown MW, Kinoshita M, Kawai C: Long-term nitrate use may be deleterious in ischemic heart disease: A study using the databases from two large-scale postinfarction studies. Multicenter Myocardial Ischemia Research Group. Am Heart J 1999, 138:577-585.

8. Genuth S, Alberti KG, Bennett P, Buse J, Defronzo R, Kahn R, Kitzmiller J, Knowler WC, Lebovitz H, Lernmark A, Nathan D, Palmer J, Rizza R, Saudek C, Shaw J, Steffes M, Stern M, Tuomilehto J, Zimmet P, Expert Committee on the Diagnosis and Classification of Diabetes Mellitus: Follow-up report on the diagnosis of diabetes mellitus. Diabetes Care 2003, 26:3160-3167.

9. Nomenclature and criteria for diagnosis of ischemic heart disease. Report of the Joint International Society and Federation of Cardiology/ World Health Organization task force on standardization of clinical nomenclature. Circulation 1979, 59:607-609.

10. ISIS-4 Collaborative gtoup: ISIS-4: a randomised factorial trial assessing early oral captopril, oral mononitrate, and intravenous magnesium sulphate in 58,050 patients with suspected acute myocardial infarction. ISIS-4 (Fourth International Study of Infarct Survival) Collaborative Group. Lancet 1995, 345:669-685.

11. Gruppo italiano per lo Studio della Spravvivenza nell'Infarto Miocardico: GISSI-3: Effects of lisinopril and transdermal glyceryl trinitrate singly and together on 6-week mortality and ventricular function after acute myocardial infarction. Lancet 1994, 343:1115-1122.

12. Takara A, Ogawa H, Endoh Y, Mori F, Yamaguchi J, Takagi A, Koyanagi R, Shiga $T$, Kasanuki $H$, Hagiwara $N$ : Long-term prognosis of diabetic patients with acute myocardial infarction in the era of acute revascularization. Cardiovasc Diabetol 2010, 9:1-7.

13. Kones R: Recent advances in the management of chronic stable angina II. Anti-ischemic therapy, options for refractory angina, risk factor reduction, and revascularization. Vasc Health Risk Manag 2010, 6:749-74.

14. Gori T, Mak SS, Kelly S, Parker JD: Evidence supporting abnormalities in nitric oxide synthase function induced by nitroglycerin in humans. J Am Coll Cardiol 2001, 38:1096-1101.

15. Kaesemeyer WH, Ogonowski AA, Jin L, Caldwell RB, Caldwell RW: Endothelial nitric oxide synthase is a site of superoxide synthesis in endothelial cells treated with glyceryl trinitrate. Br J Pharmacol 2000, 131:1019-1023.

16. Zierhut $\mathrm{W}$, Ball HA: Prevention of vascular nitroglycerin tolerance by inhibition of protein kinase C. Br J Pharmacol 1996, 119:3-5.

17. Brownlee M: The Pathobiology of Diabetic Complications: A Unifying Mechanism. Diabetes 2005, 54:1615-1625.

18. Du XL, Edelstein D, Rossetti L, Fantus IG, Goldberg H, Ziyadeh F, Wu J, Brownlee M: Hyperglycemia-induced mitochondrial superoxide overproduction activates the hexosamine pathway and induces plasminogen activator inhibitor-1 expression by increasing Sp1 glycosylation. Proc Natl Acad Sci USA 2000, 97:12222-12226.

19. Inoguchi T, Li P, Umeda F, Yu HY, Kakimoto M, Imamura M, Aoki T, Etoh T, Hashimoto T, Naruse M, Sano H, Utsumi H, Nawata H: High glucose level and free fatty acid stimulate reactive oxygen species production through protein kinase $\mathrm{C}$-dependent activation of $\mathrm{NAD}(\mathrm{P}) \mathrm{H}$ oxidase in cultured vascular cells. Diabetes 2000, 49:1939-1945.

20. Chirkov YY, Chirkova LP, Horowitz JD: Nitroglycerin Tolerance at the Platelet Level in Patients With Angina Pectoris. Am J Cardiol 1997, 80:128-131.

21. Iwase E, Tawata M, Aida K, Ozaki Y, Kume S, Satoh K, Qi R, Onaya T: A cross-sectional evaluation of spontaneous platelet aggregation in relation to complications in patients with type II diabetes mellitus. Metabolism 1998, 47:699-705.
22. Price MJ, Nayak KR, Barker CM, Kandzari DE, Teirstein PS: Predictors of heightened platelet reactivity despite dual-antiplatelet therapy in patients undergoing percutaneous coronary intervention. Am J Cardiol 2009, 103:1339-43.

23. Choi EK, Koo BK, Kim HS, Cho YM, Kang HJ, Cho YS, Chung WY, Chae $\uplus_{\text {, }}$ Choi DJ, Oh BH, Park YB, Choi YS: Prognostic significance of asymptomatic coronary artery disease in patients with diabetes and need for early revascularization therapy. Diabet Med 2007, 24:1003-11.

doi:10.1186/1475-2840-10-52

Cite this article as: Hang Yiu et al.: Long-term oral nitrate therapy is associated with adverse outcome in diabetic patients following elective percutaneous coronary intervention. Cardiovascular Diabetology 2011 10:52.

\section{Submit your next manuscript to BioMed Central and take full advantage of:}

- Convenient online submission

- Thorough peer review

- No space constraints or color figure charges

- Immediate publication on acceptance

- Inclusion in PubMed, CAS, Scopus and Google Scholar

- Research which is freely available for redistribution

Submit your manuscript at www.biomedcentral.com/submit
Biomed Central 